\title{
Cattle grazing benefits farmland bird community composition in oil palm plantations
}

\begin{abstract}
Oil palm expansion has caused considerable biodiversity loss as rainforest has been converted to plantation. However, it is still possible to mitigate such biodiversity losses and increase agricultural sustainability by introducing sustainable oil palm farming practices. One such method is the use of biological control agents for understory weed management in place of herbicides. Integrating cattle into oil palm plantation management to control undergrowth is expected to improve biodiversity (including avian diversity) in oil palm plantations. This study investigated the association between cattle grazing and farmland bird species composition in oil palm plantations. We used point transect sampling to survey farmland birds in 45 oil palm plantations which were divided into systematically and non-systematically cattle grazed plantations and control plantations (without cattle grazing). We found that both oil palm plantations with systematic $(\mathrm{P}=0.001)$ and non-systematic $(\mathrm{P}=0.005)$ cattle grazing had greater avian diversity than plantations without cattle grazing. Based on feeding guild, avian insectivores made up the majority of farmland birds observed. Bird species composition was determined by four attributes in our model: number of cattle, selective weeding frequency, age of oil palm stand, and palm height. We conclude that systematic grazing can improve avian diversity in oil palm plantations. We stress, that cattle integration into oil palm agriculture can provide an excellent means of maximising agricultural land use efficiency as well as increasing biodiversity in agricultural landscapes by increasing habitat complexity.
\end{abstract}

Keyword: Herbicides; Cattle grazing; Oil palm; Bird species composition; Sustainable agriculture 